\title{
From Excuses to Encouragements: Confronting and Overcoming the Barriers to Early Childhood Outdoor Learning in Canadian Schools
}

\author{
Heather A. Coe
}

\begin{abstract}
Heather A. Coe is a doctoral student in the Faculty of Education at Queen's University in Kingston, Ontario. Her research interests include student health and well-being, outdoor and nature-based education, and early childhood education. In addition to her graduate studies, Heather works with the Social Program Evaluation Group and has been involved in several externally funded research projects, such as the Health Behaviour in School-aged Children (HBSC) study. Before pursuing her graduate degrees, Heather worked as a kindergarten teacher at various accredited international schools in Shanghai, China. Email: heather.coe@queensu.ca
\end{abstract}

Drawing on outdoor education literature, this paper aims to address issues related to outdoor learning and to confront some of the potential barriers and concerns that educators, administrators, parents, and researchers may have with regard to outdoor learning. While forest and nature-based programs provide an ideal educational setting for children to connect and interact with the natural world, they are not always easily accessible or practical for a majority of young Canadians. There are, however, approaches and ideas that can be drawn from these specialized outdoor early years programs and applied more broadly in contemporary urban and rural Canadian schools. A conceptual shift from a culture of excuses to a model of encouragement is presented, suggesting that educators should view outdoor learning as a pedagogical and problem-solving exercise.

Keywords: nature-based education, outdoor education, environmental education, early childhood education, Canada
In recent years, a growing interest among educators, researchers, and parents has emerged regarding the need to connect young children with the natural world. In addition to cultivating environmental appreciation, empathy, and stewardship, connections and interactions with nature are essential to children's overall health and well-being (Bell, Wilson, \& Liu, 2008; Ewert, Place, \& Sibthorp, 2005). In Canada, numerous forest and nature-based early years programs have emerged across the country, offering educational environments and philosophies that embrace child-nature connections. While forest and naturebased programs provide an ideal educational setting for children to connect and interact with the natural world, they are not always easily accessible or practical for a majority of young Canadians. In addition, many educators and parents may feel uncomfortable with the idea of outdoor learning, possibly fearing that children may not be safe or that teachers will not be able the address the curriculum in a suitable manner (Copeland, Sherman, Kendeigh, Kalkwarf, \& Saelens, 2012; Munroe \& MacLellan-Mansell, 2013; Nelson, 2012). There are, however, approaches and ideas that can be drawn from these specialized outdoor early years programs and applied more broadly to contemporary urban and rural Canadian schools.

Drawing on outdoor education literature in Canada and abroad and literature specifically addressing outdoor early childhood learning in Canada, this paper aims to address issues related to outdoor learning and to confront some of the potential barriers and concerns that educators, administrators, parents, and researchers may have with regard to outdoor learning. A conceptual shift from a culture of excuses to a model of encouragement is presented, suggesting that outdoor learning should be viewed as a pedagogical and problemsolving exercise. This paper may also provide support and encouragement to educators who are implementing or seeking to integrate outdoor learning into everyday practice within contemporary Canadian schools.

\section{Learning Outdoors and the New Nature Movement}

Since its first publication in 2005, Richard Louv's Last Child in the Woods has served as a focal point and influential text within a growing movement to connect young children with the natural world. Through the introduction of terms such as nature-deficit disorder and the criminalization of natural play, Louv illuminates a changing landscape of childhood, arguing that children growing up today 
are becoming distanced and detached from the natural world. Louv asserts that the current generation of children is suffering from a "de-natured childhood" - a childhood with limited outdoor play, a childhood that is becoming increasingly sedentary, a childhood with more interaction with electronic devices than the natural environment outdoors (Louv, 2008). Through his written work and the creation of the Children \& Nature Network, Louv has launched and continues to propel a campaign that advocates for a world where every child has the opportunity to play, learn, and grow in nature (Children \& Nature Network, 2016). Davy (2012) asserts:

Through what the writer Richard Louv has called the New Nature Movement there has been an international plea to stop and think about why more children are overweight and less independent or 'risk averse', and why basic 'facts of life' such as where food comes from or the names and properties of trees or animals in the neighbourhood do not have higher priority in children's education. (p. 26)

While Louv has sparked an ever-growing dialogue and recent forms of action among child-nature advocates, the concept of connecting children with the natural world and the need for outdoor learning is not a new one. Child-nature connections have long been recognized as an important part of education. In fact, Friedrich Froebel's coining of the term kindergarten, or children's garden, in 1840 reflected his belief in the importance of outdoor learning as an integral part of every child's growth and development (Gautreau, 2009; Herrington, 2005).

Although Froebel was one of the first educators to promote and place value on children's self-initiated activities, emergent exploration, and experimentation with the outdoor physical environment, he was not the first to support child-nature connections (Herrington, 2005). In the $17^{\text {th }}$ and $18^{\text {th }}$ centuries, child-nature relationships were believed by scholars and church officials to help cultivate the development of moral values. In the $18^{\text {th }}$ century, Jean-Jacques Rousseau argued that education should take place outdoors, where learners had the opportunity to interact with and experience nature using their bodies and senses. Embracing a similar philosophy in the same century, Johann Heinrich Pestalozzi sought to help children from poor families by employing a teaching style that engaged children in the arts and agricultural activities in the natural outdoor environment. Influenced by Rousseau's and Pestalozzi's educational principles, Froebel took children outdoors to collect and investigate artifacts from the natural world. As early as 1876, John Dewey incorporated gardening and the notion of learning through experience into practice after expressing an interest in Froebel's learning gardens (Upitis, 2010).

In more recent history, modern environmental educationists such as Rachel Carson and David Sobel have further promoted child-nature connections as an integral part of education. In her 1965 book The Sense of Wonder, Rachel Carson provided a moving description and reflection on her young nephew's outdoor experiences. Carson subtly argued that children should be provided with adequate time and space to make meaningful connections with the natural world and that nature should be taught as a system of processes rather than a static condition (Norwood, 1987). Similarly, Sobel has long focused his work on place-based education and the need for children to connect with and learn from the local environments and ecologies in which they live. In a recent book, Childhood and Nature: Design Principles for Educators, Sobel (2008) argues that, with an increased emphasis on curriculum standards and test preparation, environmental education has moved away from children's first-hand experiences with nature and toward a pedagogical approach of ingesting sets of environmental facts and concepts. However, Sobel contends that "what gets lost when we focus on facts are the initiation experiences, the moments of transcendence when the borders between the natural world and ourselves break down" (p. 12). In this respect, the focus on environmental facts is occurring through the forfeiture of opportunities for children to experience the natural world - experience that Sobel argues is essential to developing the attitudes, commitment, behaviours, and pursuit of knowledge necessary for environmental conservation.

While the original traditions of kindergarten and early childhood education embrace outdoor learning and child-nature connections, time has revealed a shift from the natural world to a primarily indoor school setting - a setting that is now understood as the Canadian norm. In recent years, however, this model has begun to shift again. In alignment with Louv's new nature movement, several naturebased organizations and early years programs have been developed and implemented across the country. Offering support at the national level, the Child and Nature Alliance of Canada provides a network of organizations and individuals working to connect children and nature through education, advocacy, programming, policy, research, and the built environment (Child and Nature Alliance of Canada, n.d.). In partnership with the Child and Nature Alliance of Canada, Forest School Canada is a growing initiative that aims to connect children and nature within their educational setting by fostering rich learning experiences, ecological literacy, and healthy living (Forest School Canada, 2014a, 2014b). On a smaller scale, several forest and nature-based preschool and kindergarten programs have been developed and implemented across the country. Within these early years programs, children are fully immersed within the natural world for a majority of the school day. In some cases, children spend the entire day outdoors. While these programs are all unique, reflecting physical locality and place, they provide students with similar experiences of learning in and from local environments, woodlands, and green spaces. Based in both rural and urban communities, these schools and programs provide young children with "opportunities to 
build an on-going relationship with the land, to a dedicated educator, to one another, and to themselves" (Forest School Canada, 2014a, p. 12).

\section{Child-Nature Connections and the Benefits for Children}

In addition to having a positive impact on cognitive development (e.g., development of academic skills, Miller, 2007; improved cognitive functioning, Wells, 2000; see also Selhub \& Logan, 2012), connections and interactions with the natural world can be beneficial for children's overall health and well-being. Child-nature connections may help decrease anxiety, depression, and stress among children (Chawla, Keena, Pevec, \& Stanley, 2014; Maas et al., 2009; Wells \& Evans, 2003) and increase self-esteem, mood, and self-efficacy (Barton \& Pretty, 2010). Similarly, interactions with nature can help to increase children's concentration and attention (Mayer, Frantz, Bruehlman-Senecal, \& Dolliver, 2009; Martensson et al., 2009; Taylor \& Kuo, 2009; Taylor, Kuo, \& Sullivan, 2001). In a survey of urban primary schools, Maller (2009) found that hands-on experiences with nature were perceived by educators to contribute to a sense of achievement and empowerment among children, as well as improved self-esteem, self-confidence, engagement with school activities, and connectedness with others.

Natural environments and green schoolyards providing uniquely diverse and challenging landscapes motivate children to be physically active, often provoking their engagement in free play and risk-taking experiences (Coe, in press; Dyment \& Bell, 2008; GrigsbyToussaint, Chi, \& Fiese, 2011; Sandseter, 2009; Waters \& Maynard, 2010). These physical and challenging endeavours may support the development of coordination and physical control (Schweizer, 2009) and the improvement of gross and fine motor skills among children (Fjortoft, 2001; Fjortoft \& Sageie, 2000). In addition, outdoor play and physical engagement with the natural world have been associated with decreased childhood obesity and lowered body mass index (Bell et al., 2008; McCurdy, Winterbottom, Mehta, \& Roberts, 2010).

Just as child-nature connections are essential for children's healthy development, engagement with the natural world may help children develop empathy (Cheng \& Monroe, 2012; Kane \& Kane, 2011), responsibility (Cheng \& Monroe, 2012), and mindfulness (Howell, Dopko, Passmore, \& Buro, 2011) and cultivate environmental appreciation and stewardship (Ewert et al., 2005). In addition, a strong relationship has been found between frequent experiences with nature as a child and visits to woodlands or green spaces as an adult (Thompson, Aspinall, \& Montarzino, 2008). Similarly, positive early-life experiences with the natural world may help to cultivate an appreciation for nature and an environmental consciousness later in life (Ewert et al., 2005). In this respect, children's early interactions with nature can be viewed as a vital foundation for the cultivation of a close relationship with the natural world.

\section{Shifting From a Culture of Excuses to a Model of Encouragement}

Recognizing that child-nature connections are an essential part of a child's holistic development (Wijffels et al., 2010) and that nature plays a crucial role in the maintenance of good health and wellness, it would appear that the opportunity to experience, interact, and connect with the natural world should be a part of any child's education - whether they are educated in the forest or at any other public or private Canadian school. While many educators, administrators, and parents may believe this notion to be true, they may also possess apprehensions and concerns with regard to taking young children outdoors (Copeland et al., 2012; Munroe \& MacLellan-Mansell, 2013; Nelson, 2012). While some educators may feel limited by their own expertise or their ability to access a full spectrum of nature (such as that provided in a forest), other individuals may have concerns related to lesson planning or the achievement of curriculum goals. Apprehensions regarding erratic weather and the idea of allowing children to engage in risk-taking experiences may leave teachers and administrators feeling uncomfortable, possibly limiting their willingness to take children outdoors.

While these ideas are important concepts to consider when planning outdoor experiences for children, a genuine concern for student wellbeing should not be confused with an excuse to exclude outdoor experiences from everyday teaching and learning. Instead, the various concerns about outdoor learning that often manifest themselves as barriers can be used as a foundation to develop an authentic strategy to connect children with the natural world that is reflective of the school, environment, and community in which it is implemented. In this respect, integrating the natural world into early childhood education can be viewed as a pedagogical endeavour for teachers, where the ideas and theories embraced by forest and nature-based programs can be used as guiding lenses for educators and administrators within Canadian contemporary schools. By shifting from a culture of excuse, where concerns and apprehensions act as obstacles preventing outdoor learning, to a model of encouragement, where concerns and apprehensions are foundational in the creation of a safe and holistic educational program, a pedagogical space connecting theory and practice emerges. It is within this newly found space where the barriers to outdoor practice within Canadian schools can be overcome. 
Encouragement 1: One does not need a forest to learn about, through, and with nature. Nature is everywhere, and comes in all shapes and sizes.

For many people, nature may be perceived as a landscape untouched by human life, a space beyond urban and agricultural development where natural processes are unimpeded by human contact ("Handle With Care," 2008). However, by suggesting that nature exists where people do not presents a negative view of our role within the life cycles and ecosystems of the planet. Instead, humans are embedded in nature and should not be viewed as separate (Wickson, 2008). Nature can be viewed as the biodiversity and abundance of "natural wildness" (Louv, 2008), and is found in both urban and rural environments. Nature is anything from "loose parts in a backyard" to "a rugged mountain ridge" (Louv, 2008, p. 8), a small flower or insect in the schoolyard to a forest filled with trees. Ryden (2008) summarizes this perspective in one elegant passage: "Nature lives where we do, rather than out there somewhere beyond where the pavement ends" (p. 129).

Whether it is a field covered in grass, a garden along the side of the school, a patch of long, unkempt grass, or a lonely tree in the corner of a schoolyard, nature is everywhere, and can be used as a place and tool for learning. Interactions and experiences with these natural spaces - no matter how large or small, vast or narrow - provide children with opportunities to connect to and learn from the places, environments, and ecologies in which they live and learn. This localized educational concept reflects a theoretical idea illuminated by place-based learning, a framework often at the heart of many forest and nature-based programs. Guided by the notion that education should prepare students with the skills and desire to sustain the cultural and ecological integrity of the places they inhabit (Woodhouse \& Knapp, 2000), as well as enable them to connect learning to their own lives (Smith, 2002), place-based education strives to dissolve the boundaries between school and the local environment. Through hands-on experience and community involvement, place-based education (also known as place-conscious education; Gruenewald, 2003) strives to ground learning in local phenomena and students' lived experiences. Consequently, these experiences serve to strengthen children's connections to the places in which they live and to those with whom they share the world (Aucoin, 2011; Smith, 2002). Ann Pelo (2014) states succinctly: "Place-based learning communities expand beyond classroom walls to include the land and sky and water and their creatures, not as pretty backdrops to teaching and learning, but as the context for and content of teaching and learning" (p. 6).

In recent years, the academic work of Affrica Taylor (e.g., 2011) and Veronica Pacini-Ketchabaw (e.g., 2013) has addressed the complexity of outdoor pedagogies and the frictions and possibilities that emerge from children's encounters with nature and the more-than-human world. In one such article, Taylor and Pacini-Ketchabaw (2015) investigate the idea of interspecies learning through encounters among children, worms, and ants in Canada and Australia. Drawing on these encounters, emergent entanglements, and mutual vulnerabilities, the authors illuminate the ways in which children may learn with, rather than simply about, the natural world and other animals within their immediate and everyday common worlds. Taylor and Pacini-Ketchabaw note: "As we see it, the children are not the only orchestrators or actors in these interspecies worlds and encounters. Rather, the learning emerges from the relations taking place between all actorshuman and more-than-human alike" $(2015$, p. 2). This perspective of young children learning with nature embraces that notion that humans are inherently entangled with the lives of other worldly species, a reminder that the children (and educators) that learn with, through, and among the natural world are all "members of interconnected and interdependent multispecies common worlds" (p. 5).

Encouragement 2: One does not need to be an expert, environmentalist, or naturalist to support outdoor learning. Learning comes with and through engagement with the natural world and from each other.

David Sobel (2008) paints a grim picture of how outdoor learning is often characterized today:

In schools and at nature centers, we see just the opposite [of hands-on experiences with nature]: science units on animal taxonomy ... where students never go outside; young students being charged with the responsibility of saving endangered species; and a prevailing, Don't touch! attitude when children actually get outside. (p. 31)

Within this conceptualization, learning is framed in relation to the acquisition of specific terminology, environmental facts, and a world beyond human interaction. Furthermore, nature is viewed as something to be learned about rather than something to learn from, with, and within. With such a limited perspective in mind, it is understandable that some educators within contemporary Canadian schools may feel ill-equipped to take children outdoors - if an educator cannot repeat all of the facts or names, surely they must not "know" nature. However, a central purpose of education and hands-on experiences with the natural world is to foster curiosity and wonder among students. Such endeavours inspire children to ask questions and to make meaning of the unknown (Williams \& Brown, 2012). Similarly, children may even develop emotional, ethical, and empathetic connections with the natural world (Dickinson, 2013; Taylor \& Pacini- 
Ketchabaw, 2015).

Through hands-on experiences, learning becomes embodied; children come to understand what nature feels, smells, sounds, and sometimes even tastes likes (Hoyland \& Elliot, 2014; Pelo, 2014; Williams \& Brown, 2012). In a study conducted at a nature-based kindergarten in eastern Ontario, children were observed using their bodies and senses to explore the natural world - anything from touching and feeling snakeskin to tasting snow and ice, from smelling branches of an evergreen tree to listening to birds in the forest. While these hands-on, sensory experiences were meaningful learning opportunities in their own right, they often sparked conversation, questioning, and critical thought among the children in the class. To support student learning, the teacher within this program frequently responded to such situations with thoughtful probing and questioning to push children's thinking and by encouraging children to engage in further hands-on investigations and experimentation with nature (Coe, 2013). The teacher notes:

Children lead our activities and what they might want to do-because it's not about my agenda, it's about their agenda and their learning. When I see an opportunity for going more in-depth in their learning, expanding their knowledge, then I can kind of jump in there and use that as a springboard to move onto something else. (Coe, 2013, p. 29)

The idea of using the children's interests as a springboard for future learning is reiterated at the Sooke School District nature kindergarten in British Columbia, where children's inquiries, investigations, and ideas are central to program planning. Within this early years program, a teacher and early childhood educator work collaboratively to support children's outdoor learning, paying close attention to the theories and ideas that emerge through children's hands-on experiences with the natural world. The educators use these insights to help plan for future outdoor experiences and to conceptualize ways in which they can help to extend and deepen children's thinking and learning (Hoyland \& Elliot, 2014).

The common world interactions between young children at a childcare centre in Victoria, BC, and earthworms found in the garden, forest, and sidewalks illuminate the notion that children's encounters with the natural world are inherently pedagogical (Taylor \& Pacini-Ketchabaw, 2015). Through an ethnographic account of child-worm encounters within this Canadian setting, Taylor and PaciniKetchabaw (2015) illustrate that children's more-than-human interactions allow for learning that reaches well beyond that of simply acquiring knowledge about the natural world. While it was clear that through common world encounters children were learning how to identify the features and characteristics of earthworms and where to find them (such as by digging beside the root of a fallen cedar tree) it was also apparent that much deeper learning was occurring simultaneously. Fascinated by the worms' movements, children appeared enthralled by the small more-than-human creatures. Equally captivating were the responses that these small creatures shared with those of their human counterparts. In fact, these "multispecies pedagogies are filled with difficult decisions, unanswered questions and ethical conundrums" (Taylor \& Pacini-Ketchabaw, 2015, p. 12) as children interpret child-worm responses in individualized ways. Among the children at the $\mathrm{BC}$ childcare centre, these meaningful encounters with earthworms moved children to change their physical actions, such as treading carefully through the forest to avoid stepping on a worm, and to engage in ethical thought and conversation about life, death, and relationships among worms and humans. Within this common world, children and worms appeared to learn together as they responded in unpredictable, unexpected, and occasionally unwelcomed ways. Taylor and Pacini-Ketchabaw write: "Multispecies pedagogies explore the conditions of possibility for interspecies learning, not autonomous individual human development and learning. They are built upon relations, they stress interdependencies and they ponder the ethical and political implications of entangled human and nonhuman lives" (p. 10).

Outdoor education involves a reciprocal and collaborative relationship among the environment, students, and educators. The environment can drive and inspire children's curiosities and questions; educators can respond to the children's emergent interests by extending and expanding on their experiences (Coe, 2013; Ontario Ministry of Education Ontario, 2010, p. 121). Just as children are able to build an intimate relationship with the natural world without knowing the name of every plant, animal, or object in their environment, educators within Canadian schools can support student outdoor learning without being an expert, environmentalist, or naturalist. Rather, educators may take on other important roles, such as facilitator, advocate, role model, ally, or member of the learning community. Nelson (2012) explains that "truly engaged [early childhood] teachers are often in the background, observing and responding rather than leading. Engaged teachers support children who are initiating their own learning" (p. 12).

Trusting children to guide their own outdoor learning (Warden, 2010) does not mean that educators or other early childhood professionals cannot share their knowledge and understanding about the natural world. Nor is it to say that facts, categories, and terminology do not have a place in outdoor education. Rather, child-driven learning serves as a reminder that educators should take a reflective approach in their teaching. Pelo (2014) suggests: 
Be present and attentive to the possibilities for engaging the world, and find [the] way with awareness and intention. Does this moment call for silence or for naming? Will a shift in perspective help us see the familiar more deeply, or will it dislodge us from the intimacy of knowing? (p. 8)

Within the nature-based kindergarten program in eastern Ontario, educators found that gathering resources to help facilitate new avenues of exploration was important in supporting young children's outdoor learning. Not only did the kindergarten teacher carry a backpack equipped with items such as magnifying glasses, pencils, ropes, and guidebooks, the tent that served as an indoor classroom housed additional art supplies (e.g., paint) and resource tools (e.g., books). Through engagement with these additional materials, children were provided with the means through which to answer questions that may have emerged while the children were out in the forest or that represent their thinking and understanding of the natural world (Coe, 2013). The teacher and early childhood educator at the nature kindergarten in Sooke, BC, ventured outdoors with a similar set of tools and resources. In addition, the educators often drew on the expertise of the wider educational community to enhance student learning. Recognizing Indigenous connections to the natural world, educators invited an Indigenous support worker into their learning community on a regular basis to venture into the forest with the class and to share stories and traditional knowledge of the places in which they learned (Hoyland \& Elliot, 2014).

When embracing outdoor learning as a pedagogical activity, educators may wish to draw on experiences and examples of Canadian nature-based early years and kindergarten programs to help support outdoor learning within contemporary Canadian schools. To support children's outdoor learning, educators may wish to gather resources to help facilitate exploration. The introduction of tools such as magnifying glasses, note pads, and pencils to the outdoor environment may inspire children to examine objects of interest more closely. Coloured pencils, paint, and other art materials may serve as tools for children to use to represent their thinking and understanding of the natural world. Similarly, guidebooks, nature posters, and books about the natural world may prove to be useful educational resources and may provide answers to children's questions. Additionally, educators may wish to draw on the expertise of colleagues and the wider community to enhance student learning. School or local librarians may be able to gather a collection of books on a particular area of interest or be used as an outside expert to show children how to use books to answer their questions. If there is a school garden, educators may wish to draw on the expertise of or partner with the person or class involved in its creation and maintenance. Beyond the school, educators can draw on the knowledge and expertise of people who work at local conservation areas and wildlife centres, museums, zoos, or aquariums. Finally, educators may also wish to invite parents into the school to share their own experiences and expertise. Such school and community partnerships may not only help facilitate outdoor learning and deepen children's connections to the natural world, but also help to build an engaged community of support for outdoor programming.

\section{Encouragement 3: The curriculum does not need to be delivered indoors. Children can and do learn outdoors.}

In most contemporary Canadian schools, children spend a large portion of their day confined to the classroom. Within this context, teaching, learning, and the idea of delivering the curriculum may be assumed by many to be an indoor exercise. Children spend hours studying, playing, and learning inside the walls of the school, moving outside only at designated recess times throughout the day. Occasionally, physical education classes take place outdoors when the lesson seems appropriate (e.g., track and field or soccer). However, for the most part, the schoolyard predominantly serves as a place for children to take a break from learning.

Within Canadian teacher education programs, a similar indoor-centred perspective may be reinforced. The claim could be made that, unless otherwise instructed, teacher candidates learn to plan and deliver lessons and study units in an indoor educational environment. Within some teacher education programs, outdoor education is embraced as a specialized area of focus (e.g., the Outdoor and Experiential Education Program at Queen's University; http://educ.queensu.ca/oee). However, even within these programs the idea of outdoor education is framed as a unique form of teaching and learning and an alternative to the norm. Additionally, these outdoor-focused programs often cater to a limited number of teacher candidates and are not a part of every teacher's education. While Canadian society appears to embrace the dominant view that schooling should take place indoors, green schoolyards and naturalized outdoor environments have the potential to provide for a holistic education (Blanchet-Cohen \& Elliot, 2011). Just as the role of a teacher may need to be adapted outdoors, how teaching and learning is conceptualized may also need to be altered. Rather than relying on worksheets, math manipulatives, and new technologies, teachers can turn to the flora, fauna, and elements of the local environment as tools to help deliver and uncover the curriculum (Banning \& Sullivan, 2011; Schweizer, 2009; Wilson, 2008).

At the nature kindergarten in Sooke, educators are constantly looking for learning opportunities that may arise during children's outdoor play or adventures in the forest (Hoyland \& Elliot, 2014). Hoyland and Elliot (2014) describe the following example: 
While reading a story in a grassy clearing one morning, Lisa [the teacher] hears a Pileated Woodpecker nearby, and so do several children. Lisa stops reading to locate the woodpecker and help the children find it. This moment offers an opportunity for language development as Lisa describes how to find the woodpecker in the dead wood of the tree. (p. 40)

Along with language development, this emergent activity appears to address several other learning outcomes outlined in the BC kindergarten curriculum, such as learning about the characteristics of living things and demonstrating an ability to observe their surroundings (British Columbia Ministry of Education, 2010). In another example, researchers describe how the teacher and early childhood educator planned to extend children's thinking about a specific area of interest:

When the children showed an interest in birds, Lisa [the teacher] and Erin [the early childhood educator] provided a stimulus for a discussion about birds with the creation of a box that had a nest with an egg, some feathers, and a few pictures. This box generated a child-led discussion on birds. How you would define a bird? What had wings but wasn't a bird? From this discussion, the children created a big book on birds and what they knew about them. (Hoyland \& Elliot, 2014, p. 43)

In addition to helping children develop their knowledge and understanding about birds, the creation of a box to guide and support children's inquiries undoubtedly allowed the educators to simultaneously address several literacy outcomes. It can be conceived that the child-led discussions and questioning encouraged children to share ideas about their own experiences, build vocabulary, and experiment with language using new words or phrases. Similarly, group discussion most likely provided a forum for children to demonstrate and practice the use of good conversational and communication skills, interacting co-operatively with others and taking turns to talk and listen (British Columbia Ministry of Education, 2010). Moreover, the creation of a book almost certainly involved children crafting illustrations and engaging in some form of writing as a way to share their knowledge and understanding about birds. Not only does this exercise allow children to demonstrate their learning in a creative way and to form simple messages and illustrations to convey their thinking, it also provides an opportunity for children to gain knowledge about books themselves (e.g., understanding that books can be used as a source of knowledge; writing as a means to communicate messages; using pictures and drawings to support written meaning; British Columbia Ministry of Education, 2010).

At the nature-based kindergarten in eastern Ontario, many of the children's daily experiences reflect the learning expectations outlined in The Full-Day Early Learning-Kindergarten Program document (Coe, 2013; Ontario Ministry of Education, 2010). When examining children's experiences at this nature-based early years program, Coe (2013) found that children often exhibited acts of caring, respect, and appreciation for others, nature, and place. This observation aligns with several learning expectations outlined in the Ontario kindergarten curriculum, such as learning to identify ways in which children can care for and show respect for the environment, develop empathy, and demonstrate respect for others (Ontario Ministry of Education, 2010). Beyond the obvious connection to the environment, other curricular connections can be made. Coe describes a conversation among students sparked by the discovery of the skull of an unknown animal:

The mere sight of the skull sparks instant conversation among the children. "Maybe it's a dinosaur! A little dinosaur. Or a big animal," Jasper proposes. As the children each take turns touching and feeling the skull, they talk about the different parts of the bone. "Those teeth look like nails!" one child remarks. Comparing the skull to his teacher's head, Jasper announces, "That one's small and your head's big. It's not going to be a person." (pp. 35-36)

The narrative goes on to describe Jasper's sustained interest in the skull and describes how he and another boy ran through a list of possible animals and eliminated them based on the characteristics of the skull and what they knew about that animal (e.g., the idea of a bird is rejected because there is no beak on the skull). In addition to addressing learning expectations related to inquiry, conversation, and effective communication, this emergent learning experience touches on areas of problem solving and reasoning, and mathematical concepts, such as investigating the size and shape of nontraditional 3-dimensional objects (Ontario Ministry of Education, 2010).

The examples of student learning and curricular connections extracted from Canadian nature-based early years programs provide evidence that learning can and will happen outdoors when the opportunity is provided. However, before taking children outdoors it is essential that educators take the time to assess potential risks and plan for safety and success (Coe, in press; Hoyland \& Elliot, 2014; Knight, 2011, 2013). Part of staying safe is ensuring that children are dressed well for the weather. Educators should be cognizant of children's physical needs and help children learn to assess and care for their own well-being (e.g., what to do if they are feeling too hot; Forest School Canada, 2014a). In addition, they can familiarize themselves with the outdoor learning environment, taking note of possible risks (e.g., trees that children might want to climb) and eliminating any potential hazards (e.g., broken glass). Like the one prepared by the Sooke School District nature kindergarten, a risk management plan specific to the outdoor learning environment can be 
developed (and frequently reassessed) outlining steps to take in various situations (e.g., if someone gets hurt or stung by a bee; Hoyland \& Elliot, 2014). In both nature-based programs and contemporary school-based programs, educators can strive to not only keep children safe but also to teach children to manage particular risks for themselves (Forest School Canada, 2014a; Nelson, 2012; Stephenson, 2003). Children can be taught ways to assess and identify potential hazards (e.g., what to do if they find wild berries), and how to manage physical risk (e.g., when to ask for help). In this respect, planning for safety and success involves the creation of a community of care where safety is the responsibility of everyone involved (Coe, in press).

\section{Moving Forward}

As the new nature movement builds momentum and the dialogue surrounding child-nature connections continues to grow, the need for contemporary Canadian schools to provide children with the opportunity to learn from and in the natural world becomes ever more important. If children are to access the benefits of nature, they must be provided with meaningful experiences to interact with the natural world. Similarly, if Canadian schools are to provide a holistic education, outdoor experiences should be embraced as an important part of everyday teaching and learning. Forest and nature-based early years programs have opened the door to what is possible for outdoor learning in Canada. With guidance and encouragement from these early years programs, a conceptual shift from a culture of excuses to a model of encouragement is possible within contemporary Canadian schools. Rather than viewing concerns and apprehensions about outdoor learning as barriers for practice, educators and administrators can approach these concerns as the foundation to a safe and healthy outdoor program. Within a model of encouragement, outdoor learning becomes a pedagogical and problem-solving exercise for educators - a challenge to be embraced and not avoided.

\section{References}

Aucoin, P. J. (2011). Discovering sense of place: Application through education. Pathways, 23(3), 14-18.

Banning, W., \& Sullivan, G. (2011). Lens on outdoor learning. St. Paul, MN: Redleaf Press.

Barton, J., \& Pretty, J. (2010). What is the best dose of nature and green exercise for improving mental health? A multi-study analysis. Environmental Science \& Technology, 44, 3947-3955. doi:10.1021/es903183r

Bell, J. F., Wilson, J. S., \& Liu, G. C. (2008). Neighborhood greenness and two-year changes in body mass index of children and youth. American Journal of Preventive Medicine, 35, 547-553. doi:10.1016/j.amepre.2008.07.006

Blanchet-Cohen, N., \& Elliot, E. (2011). Young children and educators' engagement and learning outdoors: A basis for rights-based programming. Early Education and Development, 22, 757-777. doi:10.1080/10409289.2011.596460

British Columbia Ministry of Education. (2010). Kindergarten: Curriculum package. Retrieved from: http://www.bced.gov.bc.ca/irp/ curric_grade_packages/grkcurric_req.pdf

Carson, R. (1965). The sense of wonder. New York, NY: Harper \& Row.

Chawla, L., Keena, K., Pevec, I., \& Stanley, E. (2014). Green schoolyards as havens from stress and resources for resilience in childhood and adolescence. Health \& Place, 28, 1-13.

Cheng, J. C.-H., \& Monroe, M. C. (2012). Connection to nature: Children's affective attitude toward nature. Environment and Behavior, 44, 31-49. doi:10.1177/0013916510385082

Child \& Nature Network. (2016). About us. Retrieved from: http://www.childrenandnature.org/about/contact/

Child and Nature Alliance of Canada. (n.d.). About the alliance. Retrieved from: http://www.childnature.ca/about-alliance 
Coe, H. (in press). Embracing risk in the Canadian woodlands: Four children's risky play and risk-taking experiences at Canada's first forest kindergarten. Journal of Early Childhood Research.

Coe, H. (2013). A forest kindergarten: How four children experience learning and living outdoors. Unpublished master's thesis, Queen's University, Kingston, Ontario.

Copeland, K. A., Sherman, S. N., Kendeigh, C. A., Kalkwarf, H. J., \& Saelens, B. E. (2012). Societal values and policies may curtail preschool children's physical activity in child care centers. Pediatrics, 129, 265-274. doi:10.1542/peds.2011-2102

Davy, A. (2012, November/December). Forest schools. Resurgence \& Ecologist, 275, $26-27$.

Dickinson, E. (2013). The misdiagnosis: Rethinking “nature-deficit disorder." Environmental Communication, 7, 315-335. doi:10.108 $0 / 17524032.2013 .802704$

Dyment, J. E., \& Bell, A. C. (2008). Grounds for movement: Green school grounds as sites for promoting physical activity. Health Education Research, 23, 952-962. doi:10.1093/her/cym059

Ewert, A., Place, G., \& Sibthorp, J. (2005). Early-life outdoor experiences and an individual's environmental attitudes. Leisure Sciences, 27, 225-239. doi:10.1080/10490400590930853

Fjortoft, I. (2001). The natural environment as a playground for children: The impact of outdoor play activities in pre-primary school children. Early Childhood Education Journal, 29, 111-117.

Fjortoft, I., \& Sageie, J. (2000). The natural environment as a playground for children: Landscape description and analyses of a natural playscape. Landscape and Urban Planning, 48, 83-97.

Forest School Canada. (2014a). Forest and nature school in Canada: A head, heart, hands approach to outdoor learning. Retrieved from: http://www.forestschoolcanada.ca/wp-content/themes/wlf/images/FSC-Guide_web.pdf

Forest School Canada. (2014b). Forest school Canada. Retrieved from: http://www.forestschoolcanada.ca

Gautreau, J. (2009, November). Learning in the forest. Natural Life, 26-27.

Grigsby-Toussaint, D. S., Chi, S.-H., \& Fiese, B. H. (2011). Where they live, how they play: Neighborhood greenness and outdoor physical activity among preschoolers. International Journal of Health Geographics, 10(66), 1-10. doi:10.1186/1476-072X-10-66

Gruenewald, D. A. (2003). Foundations of place: A multidisciplinary framework for place-conscious education. American Educational Research Journal, 40, 619-654.

Handle with care [Editorial]. (2008). Nature, 455, 263-264. doi:10.1038/455263b

Herrington, J. (2005). The sustainable landscape. In M. Dudek (Ed.), Children 's spaces (pp. 215-244). Oxford, UK: Elsevier.

Howell, A. J., Dopko, R. L., Passmore, H.-A., \& Buro, K. (2011). Nature connectedness: Associations with well-being and mindfulness. Personality and Individual Differences, 51, 166-171.

Hoyland, T., \& Elliot, E. (2014). Nature kindergarten in Sooke: A unique collaboration. Canadian Children, 39, 39-44.

Kane, A., \& Kane, J. (2011, Fall). Waldkindergarten in Germany: How unconventional programs employ extended immersion in nature to foster empathy and stimulate intellectual development among young people. Green Teacher, 94, 16-19.

Knight, S. (2011). Risk and adventure in early years outdoor play: Learning from forest schools. London, England: SAGE.

Knight, S. (2013). Forest school and outdoor learning in the early years. London, England: SAGE. 
Louv, R. (2008). Last child in the woods: Saving our children from nature-deficit disorder (2 $2^{\text {nd }}$ ed.). Chapel Hill, NC: Algonquin Books.

Maas, J., Verheij, R. A., de Vries, S., Spreeuwenberg, P., Schellevis, F. G., \& Groenewegen, P. P. (2009). Morbidity is related to a green living environment. Journal of Epidemiology \& Community Health, 63, 967-973. doi:10.1136/jech.2008.079038

Maller, C. J. (2009). Promoting children's mental, emotional and social health through contact with nature: A model. Health Education, 109, 522-543. doi:10.1108/09654280911001185

Martensson, F., Boldemann, C., Soderstrom, M., Blennow, M., Englund, J.-E., \& Grahn, P. (2009). Outdoor environmental assessment of attention-promoting settings for preschool children. Health \& Place, 15, 1149-1157.

Mayer, F. S., Frantz, C. M., Bruehlman-Senecal, E., \& Dolliver, K. (2009). Why is nature beneficial? The role of connectedness to nature. Environment and Behavior, 41, 607-643. doi:10.1177/0013916508319745

McCurdy, L. E., Winterbottom, K. E., Mehta, S. S., \& Roberts, J. R. (2010). Using nature and outdoor activity to improve children's health. Current Problems in Pediatric and Adolescent Health Care, 5, 102-117. doi:10.1016/j.cppeds.2010.02.003

Miller, D. L. (2007). The seeds of learning: Young children develop important skills through their gardening activities at a midwestern early education program. Applied Environmental Education and Communication, 6, 49-66. doi:10.1080/15330150701318828

Munroe, E., \& MacLellan-Mansell, A. (2013). Outdoor play experiences for young First Nation children in Nova Scotia: Examining the barriers and considering some solutions. Canadian Children, 38, 25-33.

Nelson, E. M. (2012). Cultivating outdoor classrooms: Designing and implementing child-centered learning environments. St. Paul, MN: Redleaf Press.

Norwood, V. L. (1987). The nature of knowing: Rachel Carson and the American environment. Journal of Women in Culture and Society, $12,740-760$.

Ontario Ministry of Education. (2010). The full-day early learning-kindergarten program [draft version]. Toronto, ON: Author.

Pacini-Ketchabaw, V. (2013). Frictions in forest pedagogies: Common worlds in settler colonial spaces. Global Studies of Childhood, $3,355-365$.

Pelo, A. (2014). A sense of wonder: Cultivating an ecological identity in young children - and in ourselves. Canadian Children, 39, $5-10$.

Ryden, K. C. (2008). Beneath the surface: Natural landscapes, cultural meanings, and teaching about place. In L. Christensen \& H. Crimmel (Eds.), Teaching about place. Reno, NV: University of Nevada Press.

Sandseter, E. B. (2009). Characteristics of risky play. Journal of Adventure Education and Outdoor Learning, 9, 3-21. doi:10.1080/14729670802702762

Schweizer, S. (2009). Under the sky: Playing, working and enjoying adventures in the open air. East Sussex, England: Sophia Books.

Selhub, E. M., \& Logan, A. C. (2012). Your brain on nature: The science of nature's influence on your health, happiness, and vitality. Toronto, ON: HarperCollins.

Smith, G. A. (2002). Place-based education: Learning to be where we are. Phi Delta Kappan, 83, 584-594.

Sobel, D. (2008). Childhood and nature: Design principles for educators. Portland, ME: Stenhouse.

Stephenson, A. (2003). Physical risk-taking: Dangerous or endangered? Early Years, 23, 35-43. doi:10.1080/0957514032000045573 
Taylor, A. (2011). Reconceptualizing the 'nature' of childhood. Childhood, 18, 420-433. doi:10.1177/0907568211404951

Taylor, A., \& Pacini-Ketchabaw, V. (2015). Learning with children, ants, and worms in the Anthropocene: Towards a common world pedagogy of multispecies vulnerability. Pedagogy, Culture \& Society, 1-23. doi:10.1080/14681366.2015.1039050

Taylor, A. F., \& Kuo, F. E. (2009). Children with attention deficits concentrate better after walk in the park. Journal of Attention Disorders, 12, 402-409. doi:10.1177/1087054708323000

Taylor, A. F., Kuo, F., E., \& Sullivan, W. C. (2001). Coping with ADD: The surprising connection to green play settings. Environment and Behavior, 33, 54-77.

Thompson, C. W., Aspinall, P., \& Montarzino, A. (2008). The childhood factor: Adult visits to green places and the significance of childhood experience. Environment and Behavior, 40, 111-143. doi:10.1177/0013916507300119

Upitis, R. (2010). Raising a school: Foundations for school architecture. Township of South Frontenac, ON: Wintergreen Studios Press.

Warden, C. (2010). Nature kindergartens. Perthshire, England: Mindstretchers.

Waters, J., \& Maynard, T. (2010). What's so interesting outside? A study of child-initiated interaction with teachers in the natural outdoor environment. European Early Childhood Education Research Journal, 18, 473-483. doi:10.1080/1350293X.2010.525939

Wells, N. M. (2000). At home with nature: Effects of "greenness" on children's cognitive functioning. Environment and Behavior, 32, $775-795$.

Wells, N. M., \& Evans, G. W. (2003). Nearby nature: A buffer of life stress among rural children. Environment and Behavior, 35, $311-330$.

Wickson, F. (2008). What is nature, if it’s more than just a place without people? Nature, 456, 29.

Wijffels, B., Partners, C., \& Veekamp, M. (2010, January/February). Experiencing nature: An opportunity for pedagogic quality. Exchange, 191, 103-104.

Williams, D. R., \& Brown, J. D. (2012). Learning gardens and sustainability education: Bringing life to schools and schools to life. New York, NY: Routledge.

Wilson, R. (2008). Nature and young children: Encouraging creative play and learning in natural environments. New York, NY: Routledge.

Woodhouse, J. L., \& Knapp, C. E. (2000). Place-based curriculum and instruction: Outdoor and environmental education approaches. ERIC Document ED448012. Charleston, WV: ERIC Clearinghouse on Rural Education and Small Schools. Retrieved from: http://www.ericdigests.org/2001-3/place.htm 